\title{
Oncology

\section{Transparent Risk Communication in Cancer Screening: Reveal When It's Good and When It's Not}

\author{
Odette Wegwarth
}

Max Planck Institute for Human Development, Harding Center for Risk Literacy, Berlin, Germany

Public health officials, physicians, and disease advocacy groups have worked hard over many years to convince individuals of the importance of cancer screening [1]. It is practically impossible to read a major newspaper or popular magazine, watch television, or use public transportation without seeing a public service announcement promoting some form of screening. Most recently, aggressive direct-to-consumer advertising has been pitching a variety of new advanced but unproven screening tests to the public, including genetic testing for 'cancer genes'. All together, these intensive activities have created an environment unconducive to helping people understand that screening is not always good and can in fact also harm.

In spite of the growing awareness among scientific medical professionals that cancer screening is a double-edged sword some individuals may benefit from early detection, but others may be diagnosed and treated for cancer unnecessarily - this awareness has not yet reached the majority of regular doctors $[2,3]$, politicians [4] or the general public [5]. The ignorance surrounding the delicate balance of the benefits and harms of cancer screening is largely based on an intransparent communication of the effects generated in big studies.

Information on benefits and harms can be communicated in different 'currencies'. Measures such as odds ratios or relative risk are the commonly used formats. The problem with these measures is, however, that the underlying absolute risk information is concealed, and therefore readers cannot judge the clinical significance of the effect. Consider the following example: When data on Europe's first randomized controlled trial (ERSPC trial [6]) - involving 182,000 men - on the effectiveness of prostate cancer screening were published, the respective press release announced that prostate cancer screening was found to reduce the chances of dying from prostate cancer by $20 \%$. What this relative risk statement suggests to most readers is that of all people who are screened $20 \%$ less die of prostate cancer. Yet, that is not what the $20 \%$ means. In fact, a relative risk of $20 \%$ can be compatible with a wide range of changes in the absolute risk reduction of death: for example, with a reduction from 50 to 40 , from 5 to 4 , and from 0.0005 to 0.0004 . Without specifying the underlying absolute risks, i.e. the absolute numbers of prostate cancer deaths in the screening group as well as in the non-screening group, the information is incomplete [7]. Effects presented in relative terms thus communicate very little about the true and absolute size of the effect of the medical mean. Why is relative risk information so commonly used, then? Because relative risk information appears much more impressive to physicians $[8$, 9], policy makers [10], and patients [11,12] than does absolute risk information. This effect is explained by the fact that relative risk information typically yields big numbers and absolute risk information small numbers.

What then is really behind the $20 \%$ risk reduction in prostate cancer death announced by the investigators of the ERSPC trial? After an 11-year follow-up, 5 of 1,000 men in the screening group and 4 of 1,000 men in the non-screening group died of prostate cancer [13]. That is, 1 less man out of 1,000 men who regularly attended prostate cancer screening over the course of 11 years died of prostate cancer. Hence, the relative risk reduction in prostate cancer death of $20 \%$ corresponds with an absolute risk reduction of $0.1 \%$. In terms of overall mortality, the screening and non-screening groups did not differ. Unknown to most patients and unmentioned by most physicians [5], screening can also cause harm through overdiagnosis and overtreatment. Overdiagnosis is the detection of pseudodisease - screening-detected abnormalities that meet the pathologic definition of cancer but will never progress to cause symptoms in the patient's lifetime. The consequence of overdiagnosis is overtreatment - surgery or radiotherapy that provide the patient with no survival benefit but only adverse side effects of these unneeded therapies. Of

\begin{tabular}{ll}
\hline KARGER & (1) 2014 S. Karger GmbH, Freiburg \\
$2296-5270 / 14 / 3715-006 \$ 39.50 / 0$ \\
Fax +49 761 4520714 \\
$\begin{array}{l}\text { Information@Karger.com } \\
\text { www.karger.com }\end{array}$ & $\begin{array}{l}\text { Accessible online at: } \\
\text { www.karger.com/ort }\end{array}$
\end{tabular}




\begin{tabular}{|lcc|}
\hline Prostate Cancer Early Detection & \\
by PSA testing and palpation of the prostate gland & & \\
Numbers are for men aged 50 years or older, not participating vs. participating in early \\
detection for 11 years & $\begin{array}{c}1,000 \text { men } \\
\text { without }\end{array}$ & $\begin{array}{c}\mathbf{1 , 0 0 0} \text { men } \\
\text { with } \\
\text { early detection }\end{array}$ \\
Benefits & early detection \\
How many men died from prostate cancer? & 5 & 4 \\
How many men died from any cause? & 190 & 190 \\
Harms & - & 36 \\
How many men were diagnosed and treated for & & \\
prostate cancer unnecessarily? & & \\
\hline
\end{tabular}

Fig. 1. Fact box showing how the benefits and harms of prostate cancer screening can be presented in an easy to overlook and comprehensive way (source: $[13,16]$ ).

1,000 men undergoing prostate cancer screening, 36 men were found to be overdiagnosed and overtreated as a consequence of screening [13] (fig. 1).

The example of the reporting of the ERSPC trial's benefit shows that every health statistic can be reported in a transparent or misleading way. Sometimes findings on benefits and harms are reported in 2 different currencies in order to make the respective screening or treatment look more compelling to consumers (e.g., patients and physicians) and policy makers than they actually are. Usually, the benefits are then reported in relative numbers (= big numbers) and the harms in absolute numbers (= small numbers). This technique, called mismatched framing, occurs even in high-ranking medical journals [14], and from there misleading numbers disseminate to patient brochures and the media [15]. The consequence of the misleading reporting are uninformed physicians and uninformed patients who put high but unrealistic hopes in screening programs and thus are far off of making an informed decision on this issue.

What can be done? Calls for better healthcare have been typically countered by claiming that fulfilling this demand would require either raising taxes or rationing care. However, lack of money is not the problem, and more money is not the cure. The problem is a collective ignorance about which screening programs help and which do not, and the cause of this ignorance is the use of intransparent risk information about these medical means. Thus, the only cure from this 'widespread disease of medicine' is ensuring that everybody from patients to physicians to policy makers - is given absolute numbers in order to make transparent what one can expect and what not.

\section{Disclosure Statement}

The author declares no conflicts of interest.

\section{References}

1 Schwartz LM, Woloshin S, Fowler FJ, Welch HG Enthusiasm for cancer screening in the United States. JAMA 2004;291:71-78.

2 Wegwarth O, Gigerenzer G: 'There is nothing to worry about': gynecologists' counseling on mammography. Patient Educ Couns 2011;84:251-256.

3 Wegwarth O, Schwartz LM, Woloshin S, Gaissmaie W, Gigerenzer G: Do physicians understand cancer screening statistics? A national survey of primary care physicians in the United States. Ann Intern Med 2012;156:340-349.

4 Gigerenzer G, Gray JAM: Launching the century of the patient; in Gigerenzer G, Gray JAM (eds): Better Doctors, Better Patients, Better Decisions: Envisioning Healthcare 2020. Cambridge, MA MIT Press, 2012, pp 3-28.

5 Wegwarth O, Gigerenzer G: Overdiagnosis and overtreatment: evaluation of what physicians tell patients about screening harms. JAMA Intern Med 2013;173:2086-2087.
6 Schröder FH, Hugosson J, Roobol MJ, et al.: Screening and prostate-cancer mortality in a randomized European study. N Engl J Med 2009;360: 1320-1328.

7 Forrow L, Taylor WC, Arnold RM: Absolutely relative: how research results are summarized can affect treatment decisions. Am J Med 1992;92: 121-124.

8 Naylor C, Chen E, Strauss B: Measured enthusiasm: does the method of reporting trial results alter perceptions of therapeutic effectiveness? Ann Intern Med 1992;117:916-921.

-9 Fahey T, Griffith S, Peters T: Evidence based purchasing: understanding results of clinical trials and systematic reviews. BMJ 1995;311:1056-1059.

10 Hux JE, Naylor CD: Communicating the benefits of chronic preventive therapy: does the format of efficacy data determine patient's acceptance of treatment? Med Decis Making 1995;15:152-157.
11 Malenka DJ, Baron JA, Johansen S, Wahrenberger JW, Ross JM: The framing effect of relative and absolute risk. J Gen Intern Med 1993;8:543-548.

12 Schwartz LM, Woloshin S, Black WC, Welch HG: The role of numeracy in understanding the benefit of screening mammography. Ann Intern Med 1997; 127:966-972.

13 Schröder FH, Hugosson J, Roobol MJ, et al.: Prostate-cancer mortality at 11 years of follow-up. N Engl J Med 2012;366:981-990.

14 Gigerenzer G, Wegwarth O, Feufel M: Misleading communication of risk: editors should enforce transparent reporting in abstracts. BMJ 2010;341: 791-792.

15 Woloshin S, Schwartz LM: Media reporting of research presented at scientific meetings: more caution needed. Med J Aust 2006;184:576-580.

16 Ilic D, Neuberger MM, Djulbegovic M, Dahm P: Screening for prostate cancer. Cochrane Database Syst Rev 2013;1:CD004720. 